\title{
"Los vasallos se desentrañan por su rey": notas sobre quejas de curacas en el Perú del siglo XVII ${ }^{1}$
}

\author{
José de la Puente Brunke
}

Pontificia Universidad Católica del Perú

\begin{abstract}
El artículo está fundamentado en diversas quejas y peticiones formuladas por curacas al monarca en el curso de la segunda mitad del siglo XVII, y específicamente en las décadas de 1650 y de 1660. Un punto importante que se aborda es el de la política educativa de las autoridades virreinales con respecto a los "hijos de caciques", a partir de una serie de quejas en torno al funcionamiento del limeño Colegio del Príncipe, dirigido por la Compañía de Jesús. ¿Qué pretendió la Corona al insistir en la fundación de colegios para hijos de caciques? ¿Dichos planteles cumplieron las metas que se les trazó? Si bien estas dos preguntas -y sobre todo la primera - han sido contestadas por algunos autores, los testimonios que presentamos pueden plantearnos también otros interrogantes, como el referido a la sinceridad de la conversión al cristianismo de los curacas cuyas palabras recogemos. Además, el artículo ofrece algunos testimonios que pueden ayudar a conocer mejor las diversas facetas que tuvo en el Perú colonial - y en especial en el siglo XVII—la figura del curaca.
\end{abstract}

\section{Los curacas y su autoridad en el Perú colonial}

La figura del curaca sufrió en el Perú colonial grandes transformaciones: son muy notables las diferencias — tal como han señalado diversos autores- que pueden advertirse entre el curaca prehispánico y el colonial. Este último gozaba, en principio, de una "doble autoridad": si mantenía su prestigio entre la población indígena era porque ésta le reconocía una autoridad "andina", que era distinta a la que le otorgaba el sistema administrativo colonial, el cual vio en los curacas a los mejores "mediadores" entre españoles e indígenas. Además, la calidad de curaca no era hereditaria en los tiempos prehispánicos, de modo que éstos no eran estrictamente "señores", si por tales entendemos a quienes recibían esa denominación en la Europa feudal.

1 Una versión preliminar de este trabajo fue presentada en el IV Congreso Internacional de Etnohistoria, celebrado en Lima entre el 23 y el 27 de junio de 1996.

2 Pease G.Y., Franklin: Curacas, reciprocidad y riqueza. Lima, 1992, págs. 128-129 y 149. Un buen ejemplo — entre muchos que se podrían citar- del convencimiento que tenían los españoles en torno a que los curacas podían ser los mejores mediadores entre ellos y la población andina lo tenemos en unas frases de Solórzano Pereira, en las que se refería al modo en que se podría lograr que los indígenas hablaran castellano: decía que ese propósito se conseguiría "sólo con que fuesen compelidos a esto sus Caciques o Curacas; porque de ellos penden los demás" (el subrayado es nuestro). Solórzano Pereira, Juan de: Política indiana. Madrid, 1647, libro II, capítulo XXVI, n. ${ }^{\circ} 19$. 
De acuerdo con el sistema establecido por los españoles, en cambio, los curacas fueron instaurados como funcionarios hereditarios y se les dotó de diversos privilegios. Así, por ejemplo, se les exoneró del pago del tributo y - a diferencia de los "indios tributarios" - tenían toda la capacidad para efectuar transacciones económicas en la sociedad hispano-peruana sin previo permiso de las autoridades. En el fondo, el ordenamiento colonial otorgó a los curacas y a sus descendientes una posición análoga a la de los hidalgos en la España peninsular. En retribución de ese status preeminente, el curaca quedaba obligado - entre otras cosas - a responsabilizarse de la cobranza del tributo indígena. ${ }^{3}$ Igualmente, desde los inicios de la colonización se vio como prioritaria la labor de adoctrinamiento de los curacas en la fe cristiana, considerándose que de ese modo se produciría más eficazmente la propagación del Evangelio al conjunto de la población indígena, en virtud del prestigio étnico del que aquéllos gozaban. Así, los curacas tenían reservados asientos especiales en los templos, con el fin de dotar de la mayor notoriedad a su práctica cristiana. Igualmente - como afirma Scarlett O'Phelan- "estudios y ordenación fueron privilegios con los cuales se favoreció selectivamente a los hijos de los caciques pertenecientes a los principales linajes". ${ }^{4}$ Precisamente la posibilidad de la ordenación sacerdotal fue, en principio, uno de los propósitos que movió a la fundación de los colegios de hijos de caciques. ${ }^{5}$

Si bien en el propio siglo XVI no dejaron de oírse voces entre los españoles, que se manifestaban en desacuerdo con los privilegios otorgados a los curacas y que sostenían que no debía hacerse ninguna diferencia entre ellos y la población indígena en general, ${ }^{6}$ las sucesivas normas legales reafirmaron el status preeminente que desde los inicios de la coloniza-

3 Spalding, Karen: De indio a campesino. Cambios en la estructura social del Perú colonial. Lima, 1974, págs. 37-38.

4 O'Phelan Godoy, Scarlett: La gran rebelión en los Andes. De Túpac Amaru a Túpac Catari. Cusco, 1995, págs. 39 y 50-51. Sin embargo, andando el tiempo algunos de los privilegios dados a los curacas fueron recortados, creándose una situación de ambigüedad al respecto, que pudo estar — tal como afirma la propia Scarlett O'Phelan — en el origen de algunas de las conspiraciones o rebeliones en las que se vieron envueltos ciertos curacas, muy en particular en el siglo XVIII. Ibídem, pág. 29.

5 Guibovich Pérez, Pedro: "La educación en el Perú colonial: fuentes e historiografía". Histórica, XVII, n. ${ }^{\circ}$ 2, Lima, 1993, pág. 277.

6 Por ejemplo, Juan de Matienzo manifestó muy negativas opiniones con respecto a los curacas, considerando que abusaban de la población indígena con "crueldad y fiereza". Estas expresiones fueron posteriormente citadas por Solórzano Pereira, quien también recogió similar sentir en un prelado del Paraguay, para quien no tenían sentido alguno los privilegios de los curacas, ya que —en su opinión - todos los indígenas estaban creados para "obedecer y servir" por igual. Solórzano: Política indiana, lib. II, tít. XXVII, núms. 7 y 8. 
ción se les había dado. Así, por ejemplo, el virrey marqués de Montesclaros reconocía en su memoria de gobierno que los curacas eran señores de inferior condición que los incas, pero "superiores a otros particulares".7

\section{La política educativa con respecto a los hijos de curacas: el caso del Colegio del Príncipe}

\section{La creación del Colegio y su propósito:}

De acuerdo con el papel que la administración colonial otorgó a los curacas, y a la "nobleza indígena" en su conjunto, se vio como necesario, desde los primeros tiempos de la colonización, dotar a aquéllos de una “instrucción especializada”. Así, ya en 1573 Felipe II ordenó al virrey Toledo que creara en el Perú colegios para "nobles indios". ${ }^{8}$ Dicha disposición no se vio cumplida y varias décadas después, en 1616, Felipe III reiteraba esa orden al virrey príncipe de Esquilache. ${ }^{9}$ Incluso los propios caci-

7 Fuentes, M.A.: Memorias de los virreyes que han gobernado el Perú durante el tiempo del coloniaje español (Nota preliminar de ...). Lima, 1859, tomo I, pág. 19.

8 Tal como afirma Díaz Rementería, el ordenamiento español "consideró al cacique no como un indio común o del estado llano sino como partícipe del status nobiliario de la hidalguía”. Díaz Rementería, Carlos J.: El cacique en el virreinato peruano. Estudio histórico-jurídico. Sevilla, 1977, pág. 97.

9 Macera, Pablo: "Noticias sobre la enseñanza elemental en el Perú durante el siglo XVIII", en Trabajos de Historia. Lima, 1977, tomo II, págs. 239-240. Debe precisarse que el virrey Toledo estuvo de acuerdo con la fundación de colegios para hijos de caciques, al punto de que, por provisión de 21 de febrero de 1578, dispuso que se erigieran dos de esos planteles: uno en Lima, para quienes residían en la costa, y el otro en el Cuzco, para los de la sierra. Dicha disposición toledana no se hizo realidad - según supone Armas Medina- debido a que las rentas previstas por el virrey en favor de esas fundaciones fueron finalmente adjudicadas a otro colegio de parecidas características, creado en el seno de la Universidad limeña. Sin embargo, ese "colegio universitario" nunca estuvo dedicado, en la práctica, a la educación de hijos de caciques. Cfr. Armas Medina, Fernando de: Cristianización del Perú (1532-1600). Sevilla, 1953, págs. 286-287. En realidad, lo que ocurrió fue que el virrey Toledo encargó, sin éxito, la fundación del Colegio de Lima a la Universidad de San Marcos. Cfr. Cárdenas Ayaipoma, Mario: "El Colegio de Caciques y el sometimiento ideológico de los residuos de la nobleza aborigen". Revista del Archivo General de la Nación, 4/5, Lima, 1977, pág. 6; Eguiguren, Luis Antonio: Alma Mater. Orígenes de la Universidad de San Marcos (1551-1579). Lima, 1939, pág. 592. Por otro lado, se ha señalado que los dos colegios previstos por Toledo vieron demorada su creación debido a ciertos desacuerdos surgidos entre dicho virrey y el arzobispo de Lima. Cfr. O'Phelan: La gran rebelión..., pág. 53. Sobre las rentas asignadas por Toledo para los dos colegios, sabemos que dispuso que fueran tomadas de las producidas por el repartimiento de Livitaca, del que había sido encomendero Sebastián de Villafuerte y luego Jerónimo Rodríguez de Villafuerte. Según lo señalado por el virrey, de ese repartimiento se debía destinar 1,800 pesos anuales en beneficio de "dos casas y colegios para hijos de caciques, en Lima y en el Cuzco". Cfr. Puente Brunke, José de la: Encomienda y encomenderos en el Perú. Estudio social y político de una institución colonial. Sevilla, 1992, págs. 361 y 493; Valcárcel, Carlos Daniel: Historia de la educación peruana. Educación colonial. Lima, 1966, págs. 126-127. 
ques del Cuzco habían solicitado al monarca, en 1601, la creación de un "colegio de los Ingas y curacas", con el objeto de que sus hijos fuesen instruidos en la fe católica, y manifestando su deseo de que luego pudieran transmitirla a toda la población andina. ${ }^{10}$

Si bien la creación de tales colegios fue tardía en el Perú - y se produjo por reiteradas órdenes de la Corona, a diferencia de lo ocurrido en México- debe señalarse que a lo largo del siglo XVI dos instituciones religiosas destacaron por su especial interés en educar a la élite indígena, así como por su mayor disposición para incluirla en sus filas: nos referimos a los franciscanos y a los jesuitas. ${ }^{11}$ Fue en esa misma centuria cuando dos padres jesuitas redactaron las "reglas y avisos" de los colegios para hijos de caciques que habrían de fundarse ${ }^{12}$.

Fue durante el gobierno del virrey Príncipe de Esquilache cuando se creó en Lima el Colegio del Príncipe, en el barrio del Cercado, al igual que el Colegio de San Borja en el Cuzco: ambos fundados para educar a los hijos de caciques, con el propósito - según sus primeras constituciones- de brindarles una instrucción completa, que les permitiera acceder luego a los colegios mayores y tener también, eventualmente, la posibilidad — como ya hemos indicado - de alcanzar la ordenación sacerdotal. ${ }^{13}$ Según lo señalado por Xavier Albó, las actividades en este tipo de colegios estuvieron centradas en brindar a los alumnos una "sólida formación religiosa y moral", teniendo en cuenta que se buscaba que fueran los futuros catequistas; igualmente, en esos planteles se debía procurar que los alumnos conservaran las diversas costumbres propias de sus tierras, tanto en lo referido a su vestimenta cuanto, incluso, en lo tocante a la dieta alimenticia, ${ }^{14}$ todo lo cual les facilitaría la labor de transmisión de la fe cristiana a la población indígena.

El Colegio del Príncipe fue fundado en 1618, y de ello dejó puntual constancia el virrey en su memoria de gobierno:

“(...) y así habiendo cumplido con lo que Su Majestad me manda y servídose de aprobar lo hecho, dejo fundados en Santiago del Cercado de esta ciudad, un Seminario para hijos de Caciques de este Arzobispado, a cargo de los Padres de la Compañía de Jesús (...)". ${ }^{15}$

10 O'Phelan: La gran rebelión..., pág. 53.

11 Ibídem, págs. 51-52. Según afirma Xavier Albó, los franciscanos "fueron los primeros en recoger hijos de caciques en La Española y poco después en México, donde desde 1536 adquirió gran prestigio el colegio de Tlatelolco". Albó, Xavier: "Jesuitas y culturas indígenas. Perú 1568-1606. Su actitud, métodos y criterios de aculturación”. América Indígena, XXVI, n. ${ }^{\circ} 3$, México, 1966.

12 Albó: "Jesuitas....", pág. 273.

13 Macera: "Noticias...", pág. 241.

14 Albó: "Jesuitas...", pág. 275.

15 Fuentes: Memorias..., tomo I, pág. 119. 
Desde su fundación, estuvo a cargo de la Compañía de Jesús. Ya los jesuitas, desde los años de gobierno del virrey Toledo, eran los encargados de la doctrina del Cercado, y fue precisamente en ese barrio donde se fundó el "Colegio de hijos de caciques", con el propósito de que —en palabras del también jesuita Anello Oliva-

“(...) criándose con la doctrina y buena enseñanza de la Compañía puedan después darlas a sus vasallos, y por el consiguiente ser instrumentos eficaces para desarraigar la idolatría". ${ }^{16}$

El virrey Príncipe de Esquilache no ocultaba su favorable opinión con respecto a la labor de la Compañía de Jesús:

“(...) la Compañía de Jesús es de suma utilidad para todos los ministerios de la Religión, así para la extirpación de las Idolatrías, como para la enseñanza de los Indios (...)”."17

En efecto, una de las razones inmediatas que llevó a la fundación del Colegio del Príncipe fue el interés de las autoridades por lograr la definitiva extirpación de las idolatrías. Tal como afirma el P. Vargas Ugarte,

"la visita de la idolatría puso de manifiesto que uno de los medios para extirparla sería la sólida formación religiosa que se diera a los caciques y mandones de los mismos indios, por la mucha autoridad que aquéllos ejercían sobre éstos y el poder que habría de tener su ejemplo". ${ }^{18}$

Para el funcionamiento del Colegio se destinó una edificación anexa a la parroquia de Santiago del Cercado, que anteriormente había alojado un "hospital de indios", y se dispuso que para la manutención de los alumnos se utilizasen los réditos de los censos de las cajas de comunidad y los bienes de comunidad. El 1 de enero de 1619 el propio virrey impuso en la catedral de Lima, a los doce primeros alumnos, "la banda de tafetán carmesí con las armas reales y las suyas". En principio, podían ser alumnos del Colegio los mayorazgos o herederos en cada cacicazgo, aunque también podían ser recibidos los demás hijos de caciques; en esos casos, sin

16 Oliva S.J., Anello: Historia del reino y provincias del Perú, de sus Incas Reyes, Descubrimiento y Conquista por los españoles de la Corona de Castilla, con otras singularidades concernientes a la Historia. Lima, 1895, pág. 204.

17 Fuentes: Memorias..., tomo I, pág. 120. Solórzano Pereira manifestó que estando él en Lima se creó el referido colegio, y se mostró de acuerdo con que su dirección hubiese sido encomendada a la Compañía de Jesús, "por ser su Instituto acomodado para ejecutarle según se requiere, y en todas partes nos lo ha mostrado la experiencia”. Solórzano: Política indiana, lib. II, tít. XXVII, n. 43 y 44.

18 Vargas Ugarte S.J., Rubén: Historia de la Compañía de Jesús en el Perú. Burgos, 1963, tomo II (1621-1699), pág. 222. 
embargo, debían ser mantenidos por sus padres. Se dispuso que su atuendo estuviese compuesto por

“calzón y camiseta verde, de lana o algodón, media, zapatos y sombrero negro y sobre el busto llevarían cruzada la banda con las armas reales de plata, del hombro derecho al izquierdo". ${ }^{19}$

Además de instruirlos en la doctrina cristiana, el propósito del Colegio era — como resume el P. Vargas Ugarte — el de enseñar a los alumnos a leer, escribir y contar, al igual que el de adiestrarlos en la música, en el canto, en urbanidad y en "buenos modales", ${ }^{20}$

En definitiva, el Colegio buscaba conseguir de sus alumnos tanto la fidelidad a la doctrina católica como la lealtad política a las autoridades coloniales: se trataba, por tanto, de integrar a la "nobleza indígena" en el régimen colonial. ${ }^{21}$ Sin embargo, el Colegio del Príncipe tuvo, por lo general, un número corto de alumnos. La mayoría de curacas educaba a sus hijos a través de la contratación de profesores particulares. Al parecer, esto se debió fundamentalmente a razones de orden económico, ya que la manutención de cada alumno en el Colegio superaba la asignación establecida oficialmente. ${ }^{22}$

\section{Quejas de curacas sobre su funcionamiento}

El siglo XVII fue testigo de numerosas quejas de curacas peruanos, en las que reclamaban a las autoridades españolas, y al propio monarca, el cumplimiento efectivo de las preeminencias que por su status les corres-

19 Ibídem, pág. 223.

20 Vargas Ugarte S.J., Rubén: Historia de la Iglesia en el Perú. Burgos, 1959, tomo II (15701640), págs. 509-510; Historia de la Compañía de Jesús..., pág. 223.

21 Fue grande el interés de las autoridades por el aprendizaje de la lengua castellana por parte de los curacas y de sus hijos. Un ejemplo de ese interés nos lo brinda una resolución del virrey duque de la Palata — fechada el 5 de diciembre de 1683-, mediante la cual ordenaba a los corregidores de indios que fueran muy diligentes en impedir que "ninguno pueda ser cacique, gobernador, segunda persona, alcalde, ni tener ocupación alguna en el pueblo, que no sepa la lengua castellana, y la haya enseñado a sus hijos". Díaz Rementería: El cacique..., pág. 127.

22 Macera: "Noticias...", págs. 242-245. Desde su fundación hasta el momento de la expulsión de los jesuitas, pasaron por las aulas del Colegio del Príncipe en torno a setecientos alumnos. Cfr. Galdo Gutiérrez, Virgilio: Educación de los curacas. Una forma de dominación colonial. Ayacucho, 1982, pág. 46. Sin embargo, como veremos, no todos ellos fueron hijos de caciques. En sus primeros años de funcionamiento, el Colegio tuvo muy pocos alumnos (por ejemplo, en 1620 fueron doce). Después aumentó ese número, llegándose a la cifra máxima de cuarenta por año. Sin embargo, hay que tener en cuenta que no se trataba necesariamente de alumnos diferentes cada año, ya que lo habitual era que los alumnos se mantuvieran varios años. Luego de la expulsión de los jesuitas, el número de alumnos descendió considerablemente. Para entonces, se ha calculado que el promedio de alumnos que se educaron en el Colegio fue de seis por cada cinco años. Macera: "Noticias...", págs. 245-246. 
pondían, frente a eventuales atropellos que sufrían. Quizá una de las muestras más notorias del inconformismo de muchos curacas esté en el desarrollo de la rebelión o conspiración de los caciques de Lima en 1666. De ese suceso poco se sabe, pero no es muy aventurado suponer que respondió a una situación social de tensión que se manifestaba en diversos lugares del virreinato. ${ }^{23}$ Sin embargo, queremos aquí aludir a una serie de quejas relativas a un punto concreto: el funcionamiento del Colegio del Príncipe.

En efecto, en carta dirigida al monarca desde Lima el 3 de julio de 1657, dos curacas — Luis Macas y Felipe Carua Mango- recordaban los diversos documentos que con anterioridad habían enviado al Consejo de Indias no sólo los curacas, sino también el fiscal protector de los indígenas, refiriéndose a los muchos "agravios" que recibían los señores naturales. Pero los firmantes de la carta a la que aludimos decían que sólo se iban a referir a un agravio "tan digno de remedio": se trataba de una queja formal contra la administración del limeño Colegio del Príncipe por parte de los jesuitas. ${ }^{24}$

En primer lugar, manifestaban que el Colegio se había establecido en el barrio del Cercado sólo por la presión que para ello ejercieron los padres de la Compañía de Jesús, ya que — según afirmaban — la idea inicial había sido la de fundarlo en otro lugar de la ciudad. Además, se quejaban de que el rector del Colegio cobrara una "considerable" renta, que provenía "de los censos de los indios y otros efectos". ${ }^{25}$ Decían también que si a los jesuitas se les permitió establecer el Colegio de Caciques en el Cercado fue

"con cargo de que los tratase bien y que entre estos caciques no entreverase españoles, y que enseñase a leer y escribir, música y gramática y otras ciencias, que a eso se obligaron los dichos Padres". ${ }^{26}$

23 Por ejemplo, como afirma Glave, los famosos "sucesos de Laicacota", en la década de 1660, significaron algo más que una mera disputa entre grupos de españoles de diversas regiones: "las evidencias, más detenidamente analizadas, muestran ahora que se trató de una seria disputa por los recursos locales en donde todos los grupos estuvieron involucrados y donde el propio poder central fue puesto en cuestión”. Cfr. Glave, Luis Miguel: Trajinantes. Caminos indígenas en la sociedad colonial. Siglos XVI/XVII. Lima, 1989, págs. 199-201. Sobre la aludida rebelión de los caciques de Lima, véase también: Basadre, Jorge: El conde de Lemos y su tiempo (Bosquejo de una evocación y una interpretación del Perú a fines del siglo XVII). Lima, 1945, pág. 141.

24 Archivo General de Indias, Sevilla (en adelante, AGI), Lima, 169.

25 Coincidentemente, algunas décadas antes se habían alzado voces de protesta, en el Cuzco, contra el hecho de que "los censos de los indios" sirvieran para mantener el Colegio de caciques de San Borja. En este caso, fue el cabildo eclesiástico el que manifestó esa queja, considerando injusto que los pocos indígenas que estudiaban en dicho Colegio se sustentaran "con los censos del común de todos". Vargas Ugarte S.J., Rubén: Biblioteca Peruana. Manuscritos peruanos del Archivo de Indias. Lima, 1938, tomo II, págs. 110-111. Es presumible, sin embargo, que esa queja contra el Colegio de San Borja - dirigida al monarca en 1622 - respondiera también a otras motivaciones (Vargas Ugarte: Historia de la Compañía de Jesús..., pág. 225).

26 En la transcripción de los textos, hemos modernizado tanto la ortografía como la puntuación. 
Pero la principal queja de los firmantes del documento iba dirigida al hecho de que se hubiese admitido también en el Colegio a alumnos españoles. Los curacas reconocían que en los primeros años de funcionamiento los jesuitas habían cumplido con lo establecido. Sin embargo, señalaban que posteriormente el Colegio se había convertido en un establecimiento para la educación de españoles, relegándose a un segundo plano a los hijos de caciques:

"Este Colegio lo han convertido de españoles, echando a los hijos de caciques a una sala muy apartada del Colegio, muy indecente y de poca comodidad, ocupando la sala principal de los caciques a los españoles, con que los miserables no tan solamente no estudian, sino que por ser los estudiantes españoles hijos de caballeros y mercaderes, los maltratan, de suerte que están ahuyentados, y solamente y apenas les enseñan a leer y escribir".

Así pues, según los denunciantes la finalidad del Colegio del Príncipe se había desvirtuado por completo. En vista de ello, solicitaban que el Colegio de caciques se instalara en otro lugar, o que por lo menos fuera visitado un par de veces al año por el virrey —o por una persona nombrada por él- para verificar el cumplimiento de las normas que regían su funcionamiento.

Las expresiones de la mencionada carta reflejan, en primer lugar, que los curacas firmantes estaban realmente interesados en que los hijos de caciques recibieran - de acuerdo con lo previsto en las constituciones de los Colegios dirigidos a formarlos - una instrucción destinada a "hispanizarlos", con el fin de que sirvieran de adecuados "mediadores" entre la administración colonial y la población andina. Sin embargo, no podemos tomar este ejemplo como un indicio de una total adhesión al sistema colonial, ya que dicho afán pudo estar dirigido tan sólo al logro del reforzamiento de su autoridad étnica a través del reconocimiento de la misma por parte de la administración española.

En cuanto al hecho de que los jesuitas permitieran el ingreso de alumnos españoles, podríamos vincularlo - es una hipótesis - con las necesidades económicas que el funcionamiento del plantel acarreaba, ya que los alumnos españoles pagaban una pensión. ${ }^{27}$ Es posible, también, que los

27 El P. Vargas Ugarte refiere - aunque en relación al Colegio de San Borja del Cuzco- que en la década de 1690 se admitía en ese plantel el ingreso de "hijos de españoles principales de la ciudad", que pagaban 100 pesos al año y dormían en sala aparte. Vargas Ugarte: Historia de la Compañía de Jesús..., pág. 227. 
directivos del Colegio pensaran que fuera beneficioso para los hijos de caciques el trato con españoles. ${ }^{28}$ En cualquier caso, no encontramos argumentos para sostener la idea de que quienes dirigían el Colegio del Príncipe hubieran carecido de interés por instruir adecuadamente a los hijos de curacas. Es más: cuando en la década de 1630 circuló entre las autoridades españolas la idea de que los colegios de caciques eran "dañosos", los padres de la Compañía de Jesús se dirigieron al virrey conde de Chinchón, señalándole la conveniencia de mantener dichos colegios, con el fin de terminar con las "idolatrías" y de lograr que los curacas gobernaran sus pueblos "con cristiandad y policía". ${ }^{29}$

Volviendo a las quejas de 1657, el reclamo central de los curacas era el de que no hubiera más alumnos que los hijos de caciques y que, por tanto, no se tolerara la presencia de alumnos españoles:

“y estando este colegio más amparado, muchos caciques pondrán en estudio sus hijos, con la codicia de tener estudio y saber la gramática, pues están tan capaces ya muchos para cualesquiera ciencias, sin que se consienta español ninguno en este colegio, porque le es de mucho embarazo a los que estudian".

Concluían su carta solicitando al monarca que viera su petición "con ojos de piedad".

En definitiva, consideraban que los alumnos españoles perturbaban a los hijos de curacas - para quienes estaba destinado el Colegio- e impedían que éstos se educaran adecuadamente. Si bien no tenemos información precisa en cuanto al éxito o fracaso de esa petición, nos inclinamos a pensar que la situación no cambió, y que quizá fue ésa una razón adicio-

28 Se trata de una presunción, porque no nos consta que los padres jesuitas hubieran pensado eso. Quien sí lo pensó fue — por ejemplo— un canónigo, Francisco José Marán, quien dirigió el Colegio de San Borja del Cuzco tras la expulsión de los jesuitas. En testimonio recogido por Pablo Macera, dicho clérigo afirmaba que era conveniente la presencia de "españoles pobres" en el Colegio, con el fin de que los indígenas, al tratar con ellos, pudieran vencer su "pusilanimidad", así como "la cortedad y encojimiento de sus genios". Macera: "Noticias...", pág. 242.

29 Vargas Ugarte: Historia de la Compañía de Jesús..., pág. 332. Al parecer, muchos españoles consideraban perjudiciales los colegios de caciques, porque quienes estudiaban allí salían "muy ladinos". La opinión de los jesuitas —en la mencionada carta al virrey conde de Chinchón, fechada el 22 de diciembre de 1637 y reproducida por Vargas Ugarte — era otra: decían — refiriéndose a quienes habían estudiado en los colegios de caciques - que "si los condenan los Corregidores y Curas y otros españoles es por querer ellos ser señores absolutos en los pueblos y no tener quien defienda los indios y haga sus causas como las hacen estos caciques, amparándolos de las bexaciones que padecen y porque temen que acudan con sus quexas a tribunales superiores y busquen remedio a sus agravios, a lo qual acuden los caciques y no los particulares por su pusilanimidad y esta es la causa de que les parezca mal que sean ladinos y entendidos". Ibídem, págs. 332-333. 
nal que nos podría explicar el hecho - ya mencionado líneas más arribade que fueran pocos los hijos de caciques que se educaron en el Colegio del Príncipe. En este sentido - y aunque se trata de una queja bastante posterior- es pertinente referir los reclamos que en nombre de los "indios nobles" se expresaron hacia 1750, y en los que se señalaba - entre otras cosas - cómo los hijos de caciques no habían sido atendidos en su educación prácticamente durante toda la época colonial. ${ }^{30}$

\section{En pos del "verdadero conocimiento" y de la "corona de la sabiduría"}

En la aludida carta de 1657, los dos curacas firmantes manifestaban expresamente el deseo de que sus descendientes se formaran en el conocimiento de la doctrina cristiana a través de un amplio programa educativo. Obviamente, es difícil preguntarse, a través de testimonios tan particulares, sobre la sinceridad de tales afirmaciones. En todo caso, es menos discutible suponer - como ya hemos hecho antes - que los curacas aspiraban al "verdadero conocimiento" al menos como un medio para mantener esa "doble autoridad" sobre los indígenas. En ese documento consideraban, por tanto, que ese "verdadero conocimiento" podría ser alcanzado en el Colegio del Príncipe si los jesuitas prohibían el ingreso de alumnos españoles.

En cuanto a los alumnos indígenas que no eran hijos de caciques, la carta de 1657 adopta, en cambio, una postura diferente: considera que no está mal que el Colegio abra sus puertas

"a cualquiera muchacho indio que tenga sujeto capacidad para el estudio, que irá adelante en el conocimiento de la fe".

Así pues, los autores de la carta aceptan la presencia de cualquier indígena en el Colegio del Príncipe, mas no la de españoles. Además, como vemos, comparten la preocupación de la administración española por el

30 Esos reclamos, que fueron consecuencia de la rebelión de Huarochirí de mediados del siglo XVIII, son recogidos por Scarlett O’Phelan. Cfr. O'Phelan: La gran rebelión..., pág. 47. En este sentido, es interesante señalar — aunque es un dato referido al Colegio de hijos de caciques del Cuzcocómo durante la segunda mitad del siglo XVIII, en el Colegio de San Borja no sólo se admitía a hijos de caciques, sino también a vástagos de españoles y de indígenas en general. Hacia 1775 el número de hijos de caciques en ese Colegio no era mayor de 25 , mientras que el total de alumnos se acercaba a los 150. Macera: "Noticias...", pág. 242. 
logro de la propagación del cristianismo entre los indígenas. Fue muy frecuente el que los curacas insistieran en la sinceridad de su adhesión a la fe cristiana. A este respecto, es oportuno recoger otro testimonio de curacas dirigido al monarca — fechado en 1669, es decir, doce años después que el anterior- en el que negaban rotundamente que fueran "idólatras":

\footnotetext{
"que no lo somos, Señor, sino verdaderos católicos, que a pie juntillas confesamos y creemos la fe de Jesucristo Señor Nuestro, y moriremos por ella si se ofreciere ocasión". ${ }^{31}$
}

En definitiva, los testimonios mencionados trasuntan un tono de queja, tanto frente al trato que recibían los hijos de caciques, como en cuanto a las eventuales dudas que entre las autoridades coloniales surgían sobre la sinceridad de la conversión de los curacas al cristianismo y de su adhesión al "status" colonial. ${ }^{32}$ En este sentido, es oportuno recordar que en el siglo XVIII aumentaron este tipo de reclamaciones de curacas, ya que en el curso de esa centuria se restablecieron diversas restricciones para el acceso de los mestizos -incluidos los "mestizos reales", descendientes de los matrimonios mixtos de la élite indígena- a los cargos militares, a los puestos universitarios y al estamento eclesiástico. Así, los curacas del siglo XVIII consideraron que se les estaba impidiendo alcanzar "la corona de la sabiduría", por lo que se sentían "desplazados" en su propia tierra. ${ }^{33}$

En cuanto al Colegio del Príncipe, la expulsión de los jesuitas significó que su local se convirtiera en "hospital para pobres", y que un inmueble que albergaba una clínica para negros fuese habilitado como colegio para hijos de curacas. ${ }^{34}$

31 Carta de caciques a S.M. (Lima, 1-IX-1669), en AGI, Lima, 11. Los firmantes fueron: Rodrigo Rupaychahua, "cacique principal en el repartimiento de Guamantanga", su hijo Juan de Guzmán Rupaychahua, Pedro Ventura, Francisco Flores y Juan Alberto Chuquiyauri, "cacique principal" en el corregimiento de los Huamalíes.

32 En cuanto a la adhesión de la población andina al cristianismo es pertinente citar a Manuel Marzal, sobre todo porque sus afirmaciones están referidas al mismo ámbito cronológico en el que se redactaron los escritos que aquí comentamos: en efecto, dicho autor considera demostrada —en líneas generales - la transformación religiosa de la población indígena peruana hacia la segunda mitad del siglo XVII, con lo cual no podría decirse que el cristianismo de quienes integraban dicha población fuese "una simple máscara". Marzal, Manuel M.: La transformación religiosa peruana. Lima, 1983, págs. 439-440.

33 O'Phelan: La gran rebelión..., págs. 30 y 48. No olvidemos que no fue infrecuente la existencia de curacas mestizos, a pesar de que desde 1576 la Corona —al menos en teoría- decidió "no reconocer a los mestizos como titulares de la dignidad cacical". Díaz Rementería: El cacique..., pág. 132.

34 Galdo: Educación de los curacas..., pág. 46. 


\section{Los curacas y sus "increíbles molestias y trabajos"}

Ya hemos señalado cómo en el siglo XVII no fueron pocas las quejas provenientes de miembros de la élite indígena. En ese sentido, es ilustrativo glosar la antes aludida carta del 1 de septiembre de $1669,{ }^{35}$ en la que los curacas firmantes no sólo afirmaban su adhesión al cristianismo, sino que además formulaban graves denuncias en contra de diversas autoridades. En efecto, aludían a "increíbles molestias y trabajos" que padecían, originados por

"la insaciable codicia de los gobernadores y corregidores, que lo eran más para buscar intereses y propias conveniencias, tratándonos peores que a esclavos, de que se seguía con grandísimo menoscabo la disminución de los indios, y despoblación de nuestros lugares, porque sus habitadores, huyendo de la esclavitud y malos tratamientos, se han retirado en gran número a vivir como fieras en las cavernas y montes más incultos, teniéndolo por mejor suerte que el vivir entre cristianos".

Solicitaban al monarca que pusiera remedio a dicha situación. Consideraban que una razón de dichos abusos estaba en la práctica de la venta de oficios: así, los corregidores se dedicaban a recuperar el dinero gastado en la compra del oficio, y además buscaban enriquecerse, aunque fuera - decían los curacas - a costa de "nuestra sangre". En ese sentido, denunciaban los perniciosos efectos del reparto de mercancías, ${ }^{36}$ práctica que era la causa — según afirmaban — de la frecuente embriaguez de los indios. Esa denuncia es muy ilustrativa:

"Impútannos, Señor, que somos dados a la embriaguez. Cómo no lo han de ser los indios, si la principal mira de un corregidor era meter en sus pueblos gran cantidad de botijas de vino, que porque les costase más barato, compraban siempre el peor, y éste se repartía entre los pobres indios; y aunque hubiese costado a tres o cuatro pesos cuando más, se les había de dar en plata, vendida la botija, a diez pesos cuando menos. Si este vino por fuerza se repartía entre los indios, por fuerza también los habían de hacer borrachos, que no lo habían de derramar, sino consumir".

35 AGI, Lima, 11.

36 Un problema adicional que, en ocasiones, trajo el reparto de mercancías, fue que llevó a la aparición de curacas "intrusos", nombrados por los corregidores de modo arbitrario por encima de los caciques "de linaje". Ocurría probablemente en los casos en los que los curacas legítimos no facilitaban a los corregidores el desarrollo del reparto de mercancías. Así, muchos curacas "de sangre" no tuvieron otro camino que el del proceso judicial para defender su condición de tales frente a los aludidos “intrusos". Estos problemas son explicados por Scarlett O'Phelan con respecto al siglo XVIII, pero pudieron quizá empezar a darse en las últimas décadas del siglo anterior. O'Phelan: La gran rebelión..., pág. 29. 
Sin embargo, la misma carta reconocía que con la llegada del conde de Lemos al gobierno virreinal, la situación había mejorado. Así, por ejemplo, los curacas se vieron muy aliviados con lo dispuesto por dicho gobernante en el sentido de que en adelante el "entero" de la mita debía ser responsabilidad exclusiva de los corregidores. ${ }^{37}$ Hasta entonces, los curacas habían sido los únicos responsables de convocar al número requerido de indígenas para acudir a la mita ${ }^{38}$ si no lograban reunir el número establecido de mitayos, el corregidor los presionaba de diversos modos para suplir a los "faltantes". El conde de Lemos trasladó a los corregidores la responsabilidad frente al aludido "entero" de la mita; luego de reunidos los mitayos, dichos funcionarios los entregaban a los capitanes de mita, quienes debían conducirlos a Potosí. El virrey puso mucho interés en velar porque esa reforma fuese efectivamente puesta en práctica. Así, en una carta dirigida en 1670 al corregidor de Potosí, le reiteraba que

“(...) no pueden ser apremiados los indios capitanes generales, caciques y curacas a enterar los indios que no les entreguen los corregidores (...)". ${ }^{39}$

En la carta de 1669 los curacas no regateaban elogios a la labor gubernativa del conde de Lemos, de quien decían que estaba "cortado a la medida del corazón de su Dueño": no se guiaba por intereses personales, y

“(...)pone los ojos sólo en el servicio de Dios, en el de Vuestra Majestad y en nuestro provecho, aumento y defensa (...). Señor, este virrey es un apóstol, un santo en sus obras, $\mathrm{y}$ ha de dejar este reino muy restaurado, y vuelto a poblar en gran parte, de que crecerá el aumento en la labor de las minas, así de plata como de azogues, que sin indios no sólo se ha de disminuir, sino totalmente se ha de acabar". ${ }^{40}$

Consideraban, pues, que el virrey iba por el camino correcto, ya que lográndose un mejor trato para los curacas, y para los indígenas en general, serían mayores incluso las riquezas que el Perú podría ofrecer a la Corona. En efecto, afirmaban que el crecimiento económico

37 Lohmann Villena, Guillermo: El conde de Lemos, virrey del Perú. Madrid, 1946, págs. 264-265.

38 En efecto, entre las tareas de los curacas estaba la de "buscarlos y juntarlos (a los indígenas) para que vayan a las mitas". Solórzano: Política indiana, lib. II, cap. XXVII, n. ${ }^{\circ} 5$.

39 Lohmann: El conde de Lemos..., pág. 419. El conde de Lemos expresó esas mismas ideas en carta dirigida al monarca, fechada en Lima el 4 de julio de 1670 y referida específicamente a los problemas generados por la mita de Potosí. Vargas Ugarte S.J., Rubén: Pareceres jurídicos en asuntos de Indias (1601-1718). Lima,1951, págs. 155-165.

40 En este sentido, son muy ilustrativas las palabras del conde de Lemos al comprobar los padecimientos que sufrían los indígenas: "no es plata la que se lleva a España, sino sudor y sangre de indios". Lohmann: El conde de Lemos..., pág. 266. 
"depende de nuestro sudor, y los vasallos se desentrañan por su rey, cuando ven que sus ministros los tratan con amor, y los defienden y amparan".

\section{A modo de conclusión}

¿Dependía el "aumento del reino" del sudor de los curacas? Desde los inicios de la colonización, los españoles vieron en ellos a los ideales "mediadores" entre la administración española y la población indígena. También sabemos que muchas veces los propios señores naturales supieron aprovechar hábilmente su "doble autoridad" para obtener importantes beneficios.

Sin embargo, los ejemplos reseñados en este trabajo representan casos cuyo conocimiento puede brindar algunas referencias útiles en la tarea de continuar investigando - a través, precisamente, del estudio de mayor número de casos - las diversas facetas que mostró en el Perú colonial la figura del curaca. Como afirma Franklin Pease, se deben reconsiderar las actividades de los curacas teniendo en cuenta diversos factores, tales como su participación en la economía y en la organización tradicional andina, su presencia y actividad en el mercado colonial, su rol como defensores de los intereses de sus etnias, su relevancia como promotores de sublevaciones; o su papel como gestores de peticiones diversas ante las autoridades, algunas de las cuales han sido referidas en este trabajo. Y esa "reconsideración" - al decir del propio Pease- debe realizarse teniendo siempre en cuenta la actividad étnica de los curacas, y no solamente las actividades que realizaron en el ámbito de la administración española. ${ }^{41}$

Por eso mismo, de los casos presentados en estas páginas no se pueden extraer conclusiones generales, sino quizá algunas preguntas más en relación con los curacas coloniales. Preguntas que podrían relacionarse, por ejemplo, con la ya aludida rebelión de 1666, o con el testimonio - recogido por Luis Miguel Glave- que en 1639 señalaba que los curacas estaban bastante "hispanizados", y que de ellos "los más son ricos". ${ }^{42}$

41 Pease: Curacas..., págs. 166-167.

42 Glave: Trajinantes..., pág. 279. En cuanto a la "hispanización" de los curacas, y con respecto al territorio comprendido por la Audiencia de Quito, Javier Ortiz de la Tabla se ha referido a los casos de "varios caciques indígenas" que consiguieron distinciones y privilegios de las autoridades coloniales. En cuanto a los memoriales, peticiones y relaciones de méritos presentados por los curacas, el mismo autor no duda en afirmar que "por su confección, contenido y aspiraciones se advierte la identificación de valores de gran parte de los miembros de este grupo con el de beneméritos hispanos". Ortiz de la Tabla Ducasse, Javier: Los encomenderos de Quito, 1534-1660. Origen y evolución de una élite colonial. Sevilla, 1993, pág. 84. 
En realidad, no sería aventurado afirmar que en el curso del siglo XVII siguió siendo muy notable el poder de los curacas. Ya en el siglo XVIII - y particularmente en su segunda mitad, de acuerdo con lo afirmado por Scarlett O'Phelan - se produjo el adulteramiento y la crisis del sistema cacical, ${ }^{43}$ entendido como esa "medular, ambigua y, a veces trágica, posición de bisagra entre dos mundos". ${ }^{44}$ Quizá una prueba de esa crisis esté en lo afirmado por un viajero que llegó a Lima precisamente a fines del siglo XVIII, y relató —en testimonio recogido por Juan Carlos Estenssoro- lo siguiente:

"No se conocen ahora más que dos caciques, que son el de Miraflores y el de Surco, tan miserables, que están reducidos a vivir del ejercicio de enseñar en Lima a tocar instrumentos". ${ }^{45}$

43 O'Phelan: La gran rebelión..., pág. 54.

44 Glave: Trajinantes..., pág. 284.

45 Estenssoro, Juan Carlos: Música y sociedad coloniales. Lima, 1680-1830. Lima, 1989, pág. 70. ¿Habrían sido, quizá, en sus años mozos alumnos del Colegio del Príncipe? No olvidemos que entre las materias que en el Colegio se debían impartir se incluía el adiestramiento musical. En cualquier caso, y como es sabido, en los últimos tiempos del periodo colonial las autoridades procuraron despojar a los curacas o a sus descendientes de cualquier tipo de autoridad sobre la población indígena, profundizando con ellos el proceso de "castellanización”. En ese sentido, es interesante mencionar una real cédula de 15 de enero de 1792, que disponía que se fundara en Granada, en España, "un colegio de nobles americanos en el que junto a los hijos y descendientes de españoles nacidos en las Indias y los de ministros togados, intendentes y oficiales militares, nacidos en América, figurarían los hijos de caciques e indios nobles así como los mestizos nobles, con el fin de proporcionarles la educación civil y literaria que los hiciera útiles para el servicio de la Iglesia, la magistratura, la milicia y los empleos políticos”. Díaz Rementería: El cacique..., págs. 201-202. 